
\title{
25 Research Soure \\ Incidence and Risk Factors of In-hospital Prosthesis-Related Complications Following Total Shoulder Arthroplasty
}

\author{
Qinfeng Yang \\ Nanfang Hospital \\ Hao Xie \\ Nanfang Hospital \\ Shencai Liu \\ Nanfang Hospital \\ Xuanping Wu \\ Nanfang Hospital \\ Zhanjun Shi \\ Nanfang Hospital \\ Jian Wang ( $13392127531 @ 163 . c o m$ ) \\ Nanfang Hospital
}

\section{Research Article}

Keywords: Prosthesis-related complications, Total shoulder arthroplasty, Nationwide Inpatient Sample, Incidence, Risk factors, Outcomes

Posted Date: December 29th, 2021

DOI: https://doi.org/10.21203/rs.3.rs-1142426/v1

License: (9) This work is licensed under a Creative Commons Attribution 4.0 International License. Read Full License 


\section{Abstract}

\section{Background}

The occurrence of prosthesis-related complications after total shoulder arthroplasty is devastating and costly. The purpose was to determine the incidence and risk of in-hospital prosthesis-related complications after total shoulder arthroplasty utilizing a large-scale sample database.

\section{Methods}

A retrospective database analysis was performed based on Nationwide Inpatient Sample from 2010 to 2014. Patients who underwent total shoulder arthroplasty were included. Patient demographics, hospital characteristics, length of stay, economic indicators, in-hospital mortality, comorbidities, and peri-operative complications were evaluated.

\section{Results}

A total of 34,198 cases were capture from the Nationwide Inpatient Sample database. There were 343 cases of in-hospital prosthesis-related complications after total shoulder arthroplasty and the overall incidence was 1\%, with a more than 2.5-fold decrease from 2010 to 2014. Dislocation was the most common category among prosthesis-related complications $(0.1 \%)$. The occurrence of in-hospital prosthesis-related complications was associated with significantly more total charges and slightly longer length of stay while less usage of Medicare. Risk factors of prosthesis-related complications were identified including younger age ( $<64$ years), female, the native American, hospital in the South, alcohol abuse, depression, uncomplicated diabetes, diabetes with chronic complications, fluid and electrolyte disorders, metastatic cancer, neurological disorders, and renal failure. Interestingly, advanced age $(\geq 65$ years) and proprietary hospital were found as protective factors. Furthermore, prosthesis-related complications were associated with aseptic necrosis, rheumatoid arthritis, rotator cuff tear arthropathy, Parkinson's disease, prior shoulder arthroscopy, and blood transfusion.

\section{Conclusions}

It is of benefit to study risk factors of prosthesis-related complications following total shoulder arthroplasty to ensure the appropriate management and optimize consequences although a relatively low incidence was identified.

\section{Background}

Total shoulder arthroplasty (TSA) has been developed into a new stage, where TSA is a reliable optional for reducing shoulder pain and restoring function in patients for whom nonoperative management for glenohumeral arthritis has failed [1-3]. In the past decades, the prevalence of TSA and increased from $0.013 \%$ in the year 1995 to $0.197 \%$ in 2017 [4]. Whereas, implant failure and revision total shoulder arthroplasty procedures may occur commonly as a result of prosthesis-related complications (PRCs), 
such as dislocation, periprosthetic joint infection (PJI), periprosthetic fracture (PPF), and mechanical loosening of prosthetic joint $[5,6]$.

PRCs are catastrophic complications that lead to heavy burdens on the patients as well as healthcare system [4]. Early studies have demonstrated that PRCs are associated with severe pain, disability, longer length of stay (LOS), increased rates of readmission, and higher mortality $[7,8]$. Most PRCs will cause revision surgeries. Although great advancements in surgical techniques and implant design these years, the demand for shoulder arthroplasty revision procedures continues to rise [9]. It was estimated that more than 10,000 revision procedures were performed in 2017 in the United State, with a direct medical cost nearly \$205 million [4].

The reported incidence of PRCs after TSA are different largely determined by the category and follow-up time of specific adverse events, such as dislocation(0.1\%-5.6\%), mechanical loosening(0.7\%-2.19\%), PJI(0.8\%-7.27\%), and PPF(0.449\%-6.99\%) [10-16]. Therefore, with the purpose of optimizing postoperative outcomes and reducing the requirement for revision procedures after TSA, it is imperative to determine preoperatively whether patients are at high risk of early PRCs. Numerous risk factors for the above complications have been reported by prior studies [7, 9-14, 16-28].

However, there is no study currently investigating the incidence and risk factors of the in-hospital PRCs after TSA, based on a large-scale national sample. Consequently, the objective of this study was to investigate the incidence and risk factors of in-hospital PRCs following TSA, using a nationwide database.

\section{Methods}

\section{Data Source}

The data source of this study was from the Nationwide Inpatient Sample (NIS) database, which was conducted by the Healthcare Cost and Utilization Project and sponsored by the Agency for Healthcare Research and Quality. On behalf of the largest all-payer database of hospital admissions in the United States, NIS collects a stratified sample from more than 1000 hospitals, of approximately $20 \%$ of the hospitalizations in the United States each year $[9,29]$. The information, including patient demographics (age, sex, and race), hospital characteristics (type of admission and payer, and bedsize, ownership, teaching status, location, and region of hospital), LOS, total charges, in-hospital mortality, preoperative comorbidities, and diagnostic and procedural codes from International Classification of Diseases (ninth revision) Clinical Modification (ICD-9-CM) were provided by this database. This observational study used deidentified publicly available data, hence it was deemed exempt.

\section{Data Collection}

Prior to 2010, reverse shoulder arthroplasty (RSA) and anatomical TSA shared a common ICD-9-CM procedural codes $(81.80)[22,30]$. That is the 2010 year of the NIS database represents the first year that 
a separate ICD-9-CM procedural code was used to differentiate RSA (81.88) from anatomical TSA (81.80). Besides, data after the year of 2015 were not included as this was when the ICD-10 codes were first used, which may have introduced some unintended heterogeneity [31].Thus, data of this study was limitedly extracted from NIS database from 2010 to 2014. Patients undergoing anatomical TSA were identified according to ICD-9-CM procedural codes of $81.80(n=34,268)$. In-hospital PRCs were defined by ICD-9-CM diagnostic codes including dislocation (996.42), PJI (996.66/996.67/998.5/998.51/998.59), PPF (996.44), mechanical loosening (996.41/996.43/996.45), and other prosthesis-related complications (996.40/996.46/996.47/996.49/996.77/996.78/996.79). Patients who were less than 18 years old, lacked data of age, had osteomyelitis, or had pathologic fracture of humerus were excluded $(n=70)$ (Fig. 1).

The recruited cases were divided into two groups depending on the occurrence of PRCs. Patient demographics, hospital characteristics, and outcome measures (LOS, total charges, and in-hospital mortality) were assessed. The NIS database provides 29 inherent preoperative comorbidities that do not require ICD-9-CM diagnostic codes to obtain, because these inherent comorbidities have their respective variable names (Table 1). Additional comorbidities including osteoarthritis, aseptic necrosis (AN), rheumatoid arthritis (RA), rotator cuff tear arthropathy (RCTA), proximal humerus fracture, Parkinson's disease, sleep apnea, smoking, osteoporosis, and prior shoulder arthroscopy (PSA), were searched by ICD9-CM diagnostic code and analyzed at the author's discretion if they had been determined as significant risk factors for any one of the PRCs in previous studies [1, 11, 12, 14, 16, 32-35]. Perioperative complications during hospitalization were extracted from the database by ICD-9-CM diagnostic code. Medical complications included acute renal failure, acute myocardial infarction, pneumonia, pulmonary embolism, stroke, postoperative delirium, urinary tract infection, deep vein thrombosis, sepsis, postoperative shock, urinary tract infection and blood transfusion [12, 36]. Surgical complications were defined as wound dehiscence, hemorrhage/seroma/hematoma, non-healing surgical wound, and nerve injury of upper limb $[13,37]$. An additional file shows this in more details [see Additional file 1]. 
Table 1

Variables entered into the logistic regression analysis. Between line 118 and line 119

\section{Variables Specific Variables \\ Categories}

Patient

Age ( $\leq 64$ years and $\geq 65$ years), sex (male and female), race (White, Black, demographics Hispanic, Asian or Pacific Islander, Native American and Other)

Hospital characteristics

Type of admission (non-elective, elective), bed size of hospital (small, medium, large), control of hospital (collapsed category 1 [government or private], public [government, nonfederal], voluntary [private, not-for-profit], proprietary [private, investor-owned], collapsed category 2 [private]), teaching status of hospital (nonteaching, teaching), location of hospital (rural, urban), region of hospital (northeast, Midwest of north central, south, west), type of payer (Medicare, Medicaid, Private insurance, Self-pay, No charge, Other)

Comorbidities AIDS, alcohol abuse, deficiency anemia, rheumatoid diseases, chronic blood loss anemia, congestive heart failure, chronic pulmonary disease, coagulopathy, depression, diabetes (uncomplicated), diabetes (with chronic complications), drug abuse, hypertension, hypothyroidism, liver disease, lymphoma, fluid and electrolyte disorders, metastatic cancer, neurological disorders, obesity, paralysis, peripheral vascular disorders, psychoses, pulmonary circulation disorders, renal failure, solid tumor without metastasis, peptic ulcer disease, valvular disease, weight loss

\section{Data Analysis}

All the statistical analyses were performed utilizing the statistical software, $\mathrm{R}$ version 3.5.3 (The $\mathrm{R}$ Foundation Inc., Auckland, New Zealand). Significant differences between two groups were determined by Wilcoxon rank test for continuous data and chi-square test for categorical data. To identify independent risk factors of PRCs, multivariate logistic regression with the stepwise method was performed. All variables, including demographics, hospital characteristics, type of payer, and comorbidities providing by the NIS, were entered into the regression analysis (Table 1 ). Univariate and multivariate logistic regression models were constructed to evaluate the association of additional comorbidities or perioperative complications with PRCs. An alpha level of $P<0.05$ represented statistical significance. Similar analysis could be found in prior studies [38, 39].

\section{Results}

\section{Incidence of in-hospital PRCs in patients undergoing TSA}

A total of 34,198 TSAs were collected from the NIS database from 2010 to 2014 . Overall, there were 343 cases of in-hospital PRCs with an incidence of 1\% (Table 2). It was observed that the incidence of PRCs, including dislocation, PJI, PPF, mechanical loosening and others, decreased from $1.62-0.59 \%$, more than a 2.5 -fold reduction during this period (Fig. 2). Dislocation (0.1\%) was the most common PRCs after TSA, followed by PJI $(0.09 \%)$, PPF $(0.06 \%)$, and mechanical loosening $(0.03 \%)$ except for the miscellaneous (0.74\%) (Fig. 3). 
Table 2

Patient characteristics and outcomes of PRCs after TSA (2010-2014). Between line 151 and 152

\begin{tabular}{|c|c|c|c|}
\hline Parameter & No PRCs & PRCs & $\mathbf{P}$ \\
\hline Total $(\mathrm{n}=$ count $)$ & 33,855 & 343 & - \\
\hline Total incidence (\%) & 1 & & \\
\hline Age (median, years) & $68(62-75)$ & $66(57-73)$ & $<0.0001$ \\
\hline \multicolumn{4}{|l|}{ Age group (\%) } \\
\hline $18-44$ & 1.50 & 7.00 & \multirow[t]{4}{*}{$<0.0001$} \\
\hline $45-64$ & 32.73 & 39.36 & \\
\hline $65-74$ & 40.74 & 31.49 & \\
\hline$\geq 75$ & 25.03 & 22.16 & \\
\hline Sex (\% female) & 51.98 & 57.14 & 0.06 \\
\hline \multicolumn{4}{|l|}{ Race (\%) } \\
\hline White & 90.38 & 87.09 & \multirow[t]{6}{*}{0.03} \\
\hline Black & 4.18 & 4.30 & \\
\hline Hispanic & 3.00 & 4.97 & \\
\hline Asian or Pacific Islander & 0.38 & 0.66 & \\
\hline Native American & 0.36 & 1.32 & \\
\hline Other & 1.69 & 1.66 & \\
\hline Type of admission (\% elective) & 95.17 & 96.49 & 0.31 \\
\hline \multicolumn{4}{|l|}{ Bed size of hospital (\%) } \\
\hline Small & 20.98 & 21.18 & \multirow[t]{3}{*}{0.95} \\
\hline Medium & 24.36 & 25.00 & \\
\hline Large & 54.65 & 53.82 & \\
\hline \multicolumn{4}{|l|}{ Control of hospital (\%) } \\
\hline $\begin{array}{l}\text { Collapsed category } 1 \text { (government or } \\
\text { private) }\end{array}$ & 24.76 & 36.76 & \multirow[t]{3}{*}{$<0.0001$} \\
\hline Public (government, nonfederal) & 8.14 & 8.53 & \\
\hline Voluntary (private, not-for-profit) & 53.32 & 41.47 & \\
\hline
\end{tabular}

PRCs: prosthetic-related complications; TSA: total shoulder arthroplasty; LOS: length of stay 


\begin{tabular}{|c|c|c|c|}
\hline Parameter & No PRCs & PRCs & $\mathbf{P}$ \\
\hline Proprietary (private, investor-owned) & 12.01 & 10.88 & \\
\hline Collapsed category 2 (private) & 1.78 & 2.35 & \\
\hline Teaching status of hospital (\% teaching) & 51.43 & 52.65 & 0.69 \\
\hline Location of hospital (\% urban) & 90.63 & 93.24 & 0.12 \\
\hline \multicolumn{4}{|l|}{ Region of hospital (\%) } \\
\hline Northeast & 14.85 & 12.24 & \multirow[t]{4}{*}{0.003} \\
\hline Midwest or North Central & 27.82 & 20.70 & \\
\hline South & 35.40 & 42.57 & \\
\hline West & 21.93 & 24.49 & \\
\hline LOS (median, day) & $2(1-2)$ & $2(1-3)$ & $<0.0001$ \\
\hline \multirow[t]{2}{*}{ Total charges (median, \$) } & 48,950 & \multirow{2}{*}{$\begin{array}{l}56,677(40,239- \\
79,593)\end{array}$} & \multirow[t]{2}{*}{$<0.0001$} \\
\hline & $\begin{array}{l}(36,409- \\
65,546)\end{array}$ & & \\
\hline \multicolumn{4}{|l|}{ Type of payer (\%) } \\
\hline Medicare & 64.08 & 53.06 & \multirow[t]{6}{*}{0.0005} \\
\hline Medicaid & 2.21 & 2.62 & \\
\hline Private insurance & 29.62 & 34.99 & \\
\hline Self-pay & 0.34 & 0.58 & \\
\hline No charge & 0.07 & 0 & \\
\hline Other & 3.68 & 8.75 & \\
\hline In-hospital mortality (\%) & 0.05 & 0 & 1 \\
\hline
\end{tabular}

\section{Patient demographics of two groups}

Patients affected by in-hospital PRCs were 2 years younger (66 years vs 68 years) compared to the nonaffected population $(P<0.0001)$ (Table 2). Consistently, there was significant difference of the age distribution between the two groups. PRCs after TSA were $12.13 \%$ more likely to occurrence among patients younger than 64 years $(46.36 \%$ vs $34.23 \%, P<0.0001)$ (Table 2). Meanwhile, a significant difference was detected in races, with the White occupying smaller proportions $(87.09 \%$ vs $90.38 \%)$ while the Native American taking slightly larger proportions $(1.32 \%$ vs $0.36 \%)$ in the PRCs $(P=0.03)$ (Table 2$)$. 
However, no significant difference was observed in genders between two cohorts at our defined level $(P=0.06)$ (Table 2).

\section{Hospital characteristics of two groups}

It was found that the occurrence of PRCs was more likely in government or private hospital (collapsed category) (36.76\% vs $24.76 \%, P<0.0001)$, however, less likely in voluntary hospital (private, not-for-profit) (41.47\% vs 53.32\%, $P<0.0001)$ and proprietary hospital (private, investor-owned) (10.88\% vs 12.01\%, $P<0.0001)$ (Table 2). In terms of the region of hospital, in-hospital PRCs tended to occur in the South and West, whereas less likely in the Northeast and Midwest or North Central ( $P=0.003)$ (Table 2). Nevertheless, there was no statistical difference between two groups regarding to type of admission $(P=0.31)$, bedsize of hospital ( $P=0.95)$, teaching status of hospital $(P=0.69)$, and location of hospital $(P=0.12)$.

\section{Consequences of in-hospital PRCs after TSA}

There was statistical significance in the median LOS between two cohorts ( 2 days vs 2 days; $P<0.0001$ ) (Table 2). The median LOS was equal, but the interquartile range in the PRCs groups (1 days to 3 days) was still larger than the control group (1 days to 2 days), suggesting that the occurrence of PRCs slightly prolonged hospitalization (Table 2). As expected, PRCs increased medical expenditure despite the slightly longer LOS. There was a significant increase of \$7727 in total hospital charges, with the presence of inhospital PRCs $(\$ 56,677$ vs $\$ 48,950, P<0.0001)$ (Table 2$)$. With regard to the type of payer, the Medicare was observed to occupy a smaller proportion (53.06\% vs 64.08\%) while Private insurance (34.99\% vs $29.62 \%)$ and other type (8.75\% vs 3.68\%) took a larger proportion in the PRCs group ( $P=0.0005)$ (Table 2). Fortunately, patients undergoing TSA had quite low in-hospital mortality which was not affected by the presence of PRCs (Table 2).

\section{Risk factors of in-hospital PRCs after TSA}

Logistic regression analysis was applied to explore risk factors of PRCs (Table 3), and the following indicators were identified: female (odds ratio $[\mathrm{OR}]=1.45 ; 95 \%$ confidence interval $[\mathrm{CI}]=1.13-1.86 ; P=0.003$ ), the native American (OR=4.20; $\mathrm{Cl}=1.49-11.86 ; P=0.007)$, hospital in the South $(\mathrm{OR}=1.61 ; \mathrm{Cl}=1.12-2.31$; $P=0.01)$, alcohol abuse (OR=4.36; $\mathrm{Cl}=2.32-8.22 ; P<0.0001)$, depression $(\mathrm{OR}=1.48 ; \mathrm{Cl}=1.05-2.10 ; P=0.03)$, uncomplicated diabetes $(\mathrm{OR}=1.67 ; \mathrm{Cl}=1.18-2.37 ; P=0.004)$, diabetes with chronic complications $(\mathrm{OR}=2.73$; $\mathrm{Cl}=1.36-5.48 ; P=0.005)$, fluid and electrolyte disorders (OR=1.91; $\mathrm{Cl}=1.24-2.95 ; P=0.004)$, metastatic cancer $(\mathrm{OR}=16.08 ; \mathrm{Cl}=3.43-75.35 ; P=0.0004)$, neurological disorders $(\mathrm{OR}=2.02 ; \mathrm{Cl}=1.29-3.15 ; P=0.002)$, and renal failure $(\mathrm{OR}=2.15 ; \mathrm{Cl}=1.32-3.51 ; P=0.002)$. Interestingly, there were several protective factors of PRCs including advanced age ( $\geq 65$ years; $O R=0.68 ; \mathrm{Cl}=0.49-0.93 ; P=0.02$ ), public hospital $(\mathrm{OR}=0.54$; $\mathrm{Cl}=0.34-0.86 ; P=0.0091)$, voluntary hospital $(\mathrm{OR}=0.42 ; \mathrm{Cl}=0.32-0.57 ; P<0.0001)$, and proprietary hospital (OR=0.46; $\mathrm{Cl}=0.30-0.71 ; P=0.0005)$. 
Table 3

Risk factors of PRCs after TSA (2010-2014). Between line 181 and line 182

\begin{tabular}{|c|c|c|c|}
\hline Variable & OR & $95 \% \mathrm{Cl}$ & $\mathbf{P}$ \\
\hline Age $\geq 65$ years & 0.68 & $0.49-0.93$ & 0.02 \\
\hline Female & 1.45 & $1.13-1.86$ & 0.003 \\
\hline \multicolumn{4}{|l|}{ Race } \\
\hline White & Ref. & - & - \\
\hline Black & 0.88 & $0.49-1.56$ & 0.65 \\
\hline Hispanic & 1.58 & $0.92-2.70$ & 0.10 \\
\hline Asian or Pacific Islander & 1.79 & $0.43-7.41$ & 0.42 \\
\hline Native American & 4.20 & $1.49-11.86$ & 0.007 \\
\hline Other & 1.04 & $0.43-2.55$ & 0.93 \\
\hline Elective admission & 1.57 & $0.84-2.92$ & 0.15 \\
\hline \multicolumn{4}{|l|}{ Bed size of hospital } \\
\hline Small & Ref. & - & - \\
\hline Medium & 0.95 & $0.67-1.35$ & 0.79 \\
\hline Large & 0.94 & $0.69-1.28$ & 0.71 \\
\hline \multicolumn{4}{|l|}{ Control of hospital } \\
\hline Collapsed category 1 (government or private) & Ref. & - & - \\
\hline Public (government, nonfederal) & 0.54 & $0.34-0.86$ & 0.009 \\
\hline Voluntary (private, not-for-profit) & 0.42 & $0.32-0.57$ & $<0.0001$ \\
\hline Proprietary (private, investor-owned) & 0.46 & $0.30-0.71$ & 0.0005 \\
\hline Collapsed category 2 (private) & 1.29 & $0.39-4.32$ & 0.68 \\
\hline Teaching hospital & 0.84 & $0.64-1.10$ & 0.22 \\
\hline Urban hospital & 1.81 & $0.97-3.41$ & 0.06 \\
\hline \multicolumn{4}{|l|}{ Region } \\
\hline Northeast & Ref. & - & - \\
\hline
\end{tabular}

PRCs: prosthetic-related complications; TSA: total shoulder arthroplasty; OR: odds ratio; Cl: confidence interval.

Only significant comorbidities are presented. 


\begin{tabular}{|llll|}
\hline Variable & OR & $95 \%$ Cl & P \\
\hline Midwest or North Central & 0.76 & $0.49-1.18$ & 0.22 \\
\hline South & 1.61 & $1.12-2.31$ & 0.01 \\
\hline West & 1.44 & $0.96-2.17$ & 0.08 \\
\hline Type of payer & & & \\
\hline Medicare & Ref. & - & - \\
\hline Medicaid & 0.94 & $0.42-2.11$ & 0.88 \\
\hline Private insurance & 1.31 & $0.94-1.83$ & 0.11 \\
\hline Self-pay & 1.67 & $0.40-7.07$ & 0.48 \\
\hline No-charge & 0.0000 & 0.0000 & 0.97 \\
\hline Other & 2.33 & $1.43-3.79$ & 0.0007 \\
\hline Alcohol abuse & 4.36 & $2.32-8.22$ & $<0.0001$ \\
\hline Depression & 1.48 & $1.05-2.10$ & 0.03 \\
\hline Diabetes, uncomplicated & 1.67 & $1.18-2.37$ & 0.004 \\
\hline Diabetes with chronic & 2.73 & $1.36-5.48$ & 0.005 \\
\hline complications & & & 0.000 \\
\hline Fluid and electrolyte disorders & 1.91 & $1.24-2.95$ & 0.004 \\
\hline Metastatic cancer & 16.08 & $3.43-75.35$ & 0.0004 \\
\hline Neurological disorders & 2.02 & $1.29-3.15$ & 0.002 \\
\hline Renal failure & 2.15 & $1.32-3.51$ & 0.002 \\
\hline $\begin{array}{l}\text { PRCs: prosthetic-related complications; TSA: total shoulder } \\
\text { interval. }\end{array}$ & & & \\
\hline Only significant comorbidities are presented. & & & \\
\hline A d d & & & \\
\hline
\end{tabular}

\section{Additional comorbidities and complications associated with in-hospital PRCs after TSA}

As for the indications for TSA, patients diagnosed with osteoarthritis were less likely to experience inhospital PRCs $(P=0.0005)$ (Table 4). Nevertheless, those diagnosed with AN, RA, and RCTA receiving TSA were more likely to experience in-hospital PRCs $(P=0.0005)$ (Table 4). Additionally, PRCs after TSA tended to occur in patients with history of PSA $(P=0.03)$ (Table 4). In multivariate analysis, $\mathrm{AN}(\mathrm{OR}=7.15 ; \mathrm{Cl}=4.24$ 12.06; $P<0.0001)$, RA (OR=3.08; $\mathrm{Cl}=1.35-6.99 ; P=0.007)$, and RCTA (OR=2.21; $\mathrm{Cl}=1.38-3.57 ; P=0.001)$ 
compared with osteoarthritis, Parkinson's disease ( $\mathrm{OR}=3.21 ; \mathrm{Cl}=1.30-7.90 ; P=0.01)$, and PSA (OR=13.63; $\mathrm{Cl}=3.17-58.70 ; P=0.0005$ ) were independent risk factors for PRCs after TSA (Table 4).

Table 4

Additional comorbidities associated with PRCs after TSA (2010-2014). Between line 196 and line 197

\begin{tabular}{|c|c|c|c|c|c|c|}
\hline \multirow[t]{2}{*}{ Comorbidity } & \multicolumn{3}{|c|}{ Univariate Analysis } & \multicolumn{3}{|c|}{$\begin{array}{l}\text { Multivariate Logistic } \\
\text { Regression }\end{array}$} \\
\hline & NO PRCs & PRCs & $\mathbf{P}$ & OR & $95 \% \mathrm{Cl}$ & $\mathbf{P}$ \\
\hline \multicolumn{7}{|l|}{ Indications for TSA } \\
\hline Osteoarthritis & $\begin{array}{l}30,229 \\
(92.29 \%)\end{array}$ & $\begin{array}{l}187 \\
(81.30 \%)\end{array}$ & 0.0005 & Ref. & - & - \\
\hline Aseptic necrosis & $363(1.11 \%)$ & $16(6.96 \%)$ & 0.0005 & 7.15 & $\begin{array}{l}4.24- \\
12.06\end{array}$ & $<0.0001$ \\
\hline Rheumatoid arthritis & $319(0.97 \%)$ & $6(2.61 \%)$ & 0.0005 & 3.08 & $\begin{array}{l}1.35- \\
6.99\end{array}$ & 0.007 \\
\hline $\begin{array}{l}\text { Rotator cuff tear } \\
\text { arthropathy }\end{array}$ & $1390(4.24 \%)$ & $19(8.26 \%)$ & 0.0005 & 2.21 & $\begin{array}{l}1.38- \\
3.57\end{array}$ & 0.001 \\
\hline $\begin{array}{l}\text { Proximal humerus } \\
\text { fracture }\end{array}$ & 455 (1.39\%) & $2(0.87 \%)$ & 0.0005 & 0.71 & $\begin{array}{l}0.17- \\
2.86\end{array}$ & 0.63 \\
\hline \multicolumn{7}{|l|}{ Other comorbidities } \\
\hline Parkinson's disease & $250(0.74 \%)$ & $5(1.46 \%)$ & 0.11 & 3.21 & $\begin{array}{l}1.30- \\
7.90\end{array}$ & 0.01 \\
\hline Sleep apnea & $\begin{array}{l}4644 \\
(13.72 \%)\end{array}$ & $\begin{array}{l}42 \\
(12.24 \%)\end{array}$ & 0.48 & 0.99 & $\begin{array}{l}0.68- \\
1.45\end{array}$ & 0.98 \\
\hline Smoking & $7551(22.3 \%)$ & $\begin{array}{l}82 \\
(23.91 \%)\end{array}$ & 0.52 & 1.07 & $\begin{array}{l}0.79- \\
1.46\end{array}$ & 0.66 \\
\hline Osteoporosis & 1689 (4.99\%) & $24(7 \%)$ & 0.12 & 0.91 & $\begin{array}{l}0.49- \\
1.67\end{array}$ & 0.76 \\
\hline $\begin{array}{l}\text { Prior shoulder } \\
\text { arthroscopy }\end{array}$ & $24(0.07 \%)$ & $2(0.58 \%)$ & 0.03 & 13.63 & $\begin{array}{l}3.17- \\
58.70\end{array}$ & 0.0005 \\
\hline
\end{tabular}

PRCs: prosthetic-related complications; TSA: total shoulder arthroplasty; OR: odds ratio; Cl: confidence interval.

Univariate analysis showed that patients with in-hospital PRCs were more likely to have either medical perioperative complications including pneumonia, postoperative delirium, urinary tract infection, sepsis, and blood transfusion or surgical complications merely including wound dehiscence compared with those without PRCs (Table 5). However, multivariate analysis only found that in-hospital PRCs were independently associated with blood transfusion ( $\mathrm{OR}=2.61 ; \mathrm{Cl}=1.38-4.92 ; P=0.003)$ among all the perioperative complications. 
Table 5

Complications associated with PRCs after TSA (2010-2014). Between line 207 and line 208

\section{Complications}

Univariate Analysis

No PRCs PRCs
Multivariate Logistic

Regression
OR $\quad 95 \% \quad P$

$\mathrm{Cl}$

\section{Medical complications}

Acute renal failure

425

$8 \quad 0.08$

1.00

$0.45-$

0.99

$(1.26 \%) \quad(2.33 \%)$

2.19

Acute myocardial infarction

157

$\begin{array}{ll}2 & 0.68\end{array}$

0.67

$0.16-$

0.58

$(0.46 \%) \quad(0.58 \%)$

Pneumonia

127

$4 \quad 0.04$

1.47

2.85

$(0.38 \%) \quad(1.17 \%)$

0.47

4.54

Pulmonary embolism

37

1

0.32

1.89

0.23

15.36

Stroke

207

$(0.29 \%)$

0.06

1.74

$0.64-$

$(0.61 \%) \quad(1.46 \%)$

4.70

Postoperative delirium

183

$(0.54 \%)$

5

$(1.46 \%)$

0.04

1.57

$0.61-$

4.07

Urinary tract infection

588

$(1.74 \%)$

16

$(4.66 \%)$

0.0001

1.91

0.98

3.75

Deep vein thrombosis

$$
33
$$

$(0.1 \%)$

(0.29\%)

0.29

1.14

0.14- $\quad 0.90$

Sepsis

18

$(0.05 \%)$

$\begin{array}{ll}2 & 0.02\end{array}$

4.99

9.45

Postoperative shock

9
$(0.03 \%)$

Continuous invasive mechanical

ventilation

61
$(0.18 \%)$

Blood transfusion

(0.18\%)

$0(0 \%)$

1

(0.03\%)

$\begin{array}{ll}1 & 0.47\end{array}$

1238

$(0.29 \%)$

0.47

0.49

0.06- $\quad 0.52$

4.24

$0.96-\quad 0.06$

26.10

(3.66\%)

40

(11.66\%)

$<0.0001$

2.61

$1.38-$

4.92

Any medical complication ${ }^{a}$

$\begin{array}{ll}2600 & 64 \\ (7.68 \%) & (18.66 \%)\end{array}$

$<0.0001$

1.27

$0.66-$

2.44

\section{Surgical complications}

PRCs: prosthetic-related complications; TSA: total shoulder arthroplasty; OR: odds ratio; $\mathrm{Cl}$ : confidence interval.

Any medical complication ${ }^{\mathrm{a}}$ or surgical complication ${ }^{\mathrm{b}}$ : patients with more than one complication are counted only once. 


\begin{tabular}{|c|c|c|c|c|c|c|}
\hline \multirow[t]{2}{*}{ Complications } & \multicolumn{3}{|c|}{ Univariate Analysis } & \multicolumn{3}{|c|}{$\begin{array}{l}\text { Multivariate Logistic } \\
\text { Regression }\end{array}$} \\
\hline & No PRCs & PRCs & $\mathbf{P}$ & OR & $\begin{array}{l}95 \% \\
\mathrm{Cl}\end{array}$ & $\mathbf{P}$ \\
\hline Wound dehiscence & $\begin{array}{l}3 \\
(0.01 \%)\end{array}$ & $\begin{array}{l}1 \\
(0.29 \%)\end{array}$ & 0.04 & 0.0000 & $\mathrm{n} / \mathrm{a}$ & 0.99 \\
\hline Hemorrhage/seroma/hematoma & $\begin{array}{l}90 \\
(0.27 \%)\end{array}$ & $\begin{array}{l}1 \\
(0.29 \%)\end{array}$ & 0.60 & 0.0000 & $\mathrm{n} / \mathrm{a}$ & 0.99 \\
\hline Non-healing surgical wound & $\begin{array}{l}4 \\
(0.01 \%)\end{array}$ & $0(0 \%)$ & 1 & 0.0000 & $\mathrm{n} / \mathrm{a}$ & 0.99 \\
\hline Nerve injury of upper limb & $\begin{array}{l}22 \\
(0.06 \%)\end{array}$ & $0(0 \%)$ & 1 & 0.0000 & $\mathrm{n} / \mathrm{a}$ & 0.99 \\
\hline Any surgical complication ${ }^{b}$ & $\begin{array}{l}118 \\
(0.35 \%)\end{array}$ & $\begin{array}{l}2 \\
(0.58 \%)\end{array}$ & 0.34 & 2073535 & $\mathrm{n} / \mathrm{a}$ & 0.99 \\
\hline \multicolumn{7}{|c|}{$\begin{array}{l}\text { PRCs: prosthetic-related complications; TSA: total shoulder arthroplasty; OR: odds ratio; Cl: confidence } \\
\text { interval. }\end{array}$} \\
\hline \multicolumn{7}{|c|}{$\begin{array}{l}\text { Any medical complication }{ }^{\mathrm{a}} \text { or surgical complication }{ }^{\mathrm{b}} \text { : patients with more than one complication are } \\
\text { counted only once. }\end{array}$} \\
\hline
\end{tabular}

\section{Discussion}

The present study provides a large-scale as well as health-economic analysis of in-hospital PRCs after TSA. With more attention on improving surgical techniques and component design, the incidence of PRCs following TSA decreased from 2010 to 2014 with an exceeding 2.5-fold reduction (Fig. 1). An overall incidence of $1 \%$ of in-hospital PRCs after TSA was firstly identified in this study because previous studies mainly focused on the specific categories of PRCs. Interestingly, this overall incidence of in-hospital PRCs following TSA was lower than that following total hip arthroplasty (THA) $(1.96 \%)$ while higher than that following total knee arthroplasty (TKA) $(0.69 \%)[38,39]$. It was found that the dislocation of prosthetic joint was the most common PRCs, followed by PJI, PPF, and mechanical loosening (Fig. 2), which were to a large extent consistent with the previous studies on implant failure after shoulder arthroplasty $[12,14$, 15, 35]. Coincidentally, the prior study conducted by our authors found the same results that dislocation was the most common PRCs, followed by PJI, PPF and mechanical loosening after THA [39]. This consistency between TSA and THA reflect the similarity of these two procedures.

A previous literature reported that male was a significant risk factor for revision shoulder arthroplasty, nonetheless in this study, female was identified as a risk factor of PRCs in logistic regression analysis [6]. This disparity may be due to that our study was the analysis of in-hospital PRCs after TSA which was an early stage or even unsure to require revision. Besides, female patients undergoing shoulder arthroplasty were associated with receiving blood transfusion which was at high risk of PRCs in this study [22]. Furthermore, female was reported to be susceptible to suffer from depression which was also a risk 
factor of PRCs in our results [40]. Patients with PRCs were 2 years younger than those without. Besides, from the perspective of age distribution, patients younger than 64 years accounted for a greater proportion in the PRCs group. In addition, in logistic regression analysis, advanced age ( $\geq 65$ years) was identified as a protective factor of PRCs. On the contrary, younger age ( $<64$ years) could statistically be determined as a risk factor of PRCs. To a great extent, this is consistent with previous studies which identified younger age as an independent predictor of PJI, failure or revision after shoulder arthroplasty [6, $10,11,14,17,24,28,30]$. The etiology underlying this finding is unclear, but this can be used to educate patients, inform surgeons when counseling younger patients regarding their risks, and serve as an impetus for further investigation [24]. Reasons for the Native American patients more likely and risky to experience PRCs are unknown and likely multifactorial. It is possibly that these minority populations have lower levels of cultural and healthy literacy. Therefore, these patients tend to receive lower-quality care or have difficulty understanding and complying with postoperative instructions [41, 42].

Compared with the Northeast region of the United States, hospital in the South was associated with an increased likelihood of PRCs, similar to our prior findings discussing about the PRCs following THA [39]. Combined with the univariate analysis and multivariate analysis, patients in voluntary hospital were less likely and risky to experience PRCs. However, the reasons for these two hospital characteristic remain unclear and require further research.

Both the median LOS was 2 days no matter whether the in-hospital PRCs occurred, which is in line with prior studies that also found an mean LOS of approximate 2 days in patients undergoing TSA [29, 33]. Although the interquartile range of LOS presented statistical significance between two groups, this small difference was not obvious and might not be clinically important or meaningful [40]. Luckily, the occurrence of in-hospital PRCs after TSA did not incur patients to death in this study, totally unlike to our previous findings in terms of THA and TKA, suggesting that TSA is safer as well as less traumatic to individuals compared with the other two procedures [38, 39]. Even so, the presence of PRCs still increased total charge during hospitalization, due to the costly treatments and cares of these complications $[8,10]$.

To moderate these costly events and further reduce the need for revision, preoperative identification of patients at increased risk of in-hospital PRCs after TSA is essential [43,44]. Logistic regression was performed and several risk factors of in-hospital PRCs following TSA were identified (Table 3, 4, and 5). Similar to our prior study on PRCs after THA, patients with alcohol abuse were at high risk of PRCs after TSA, probably because excessive alcohol consumption is associated with weakened immune system and mechanisms, impaired phagocytic function, or induced cytokine abnormalities which may have a relationship with PJI $[26,39]$. Depression has previously been reported to be associated with a series of adverse outcomes, such as PJI, sepsis, wound complications, return to the operating room for irrigation and debridement, extended LOS, readmission, revision surgery, and greater health care utilization after TSA, in-hospital PRCs after THA and TKA [38-40,45]. Although the relationship between depression and in-hospital PRCs after TSA may seem obscure, imbalance of immune system inducing PJI likely explain this. Psychological distress produces a systemic state of inflammation leading to dysregulation of the immune system and a resultant susceptible host state [45]. Additionally, depression itself may influence 
T-cell phenotype, and antidepressant medications have been shown to have negative immunoregulatory effects, further causing immune susceptibility [40].

Diabetic patients with vulnerable defenses against bacteria, or impaired wound healing because microangiopathic changes could reduce the tissue concentrations of antibiotics as well as cause local tissue ischemia, consequently are susceptible to PJI, and in-hospital PRCs following TSA, THA and TKA $[38,39,46]$. In concordance with our previous results, metastatic cancer in this study conferred the highest OR value (Table 3 ). This severe comorbidity possibly predisposes patients to PJI because of immunosuppressive conditions [38, 39]. Patients with either neurological disorders or Parkinson disease were at increased risk of PRCs likely because of the increased tone of the shoulder girdle musculature, the difficulties with rehabilitation, and stretching of the rotator cuff-capsule arthrotomy site, particularly the rotator interval [14]. Besides, patients with Parkinson's disease lack complete volitional muscular control and have asynchronous motor function, they appear to place the shoulder at high risk for instability [14, 39]. Additionally, constant tremors may result in implant loosening, which further increases the dislocation risk [14]. Intriguingly, fluid and electrolyte disorders not only increase the odds of PRCs after THA and TKA, but also had an increased risk of PRCs after TSA [38, 39]. Renal failure has been reported as a significant risks factor for surgical site infection and revision following TSA [6, 8]. Patients with these two comorbidities to some degree may reflect the weakened status and insufficient immune function, and hence surgeons should be more cognizant of perioperative nephrotoxic medications, intraoperative hypotensive anesthesia, and postoperative fluid management in this complex patient population [47].

As expected, patients with indications for TSA such as AN, RA, or RCTA had higher odds of PRCs compared with osteoarthritis. Consistently, AN has been associated with a significantly increased risk for postoperative infection, dislocation, fracture, and revision surgery after TSA [16]. Despite our authors previously reported that RA was associated with in-hospital PRCs following THA, it was firstly found in this study that patients RA undergoing TSA were risky to experience in-hospital PRCs [39]. Corticosteroid therapy, alcohol abuse, immunosuppressive conditions, or posttraumatic poor soft tissue bed may partially explain the association of in-hospital PRCs with AN and RA [8, 16, 17, 26, 39]. Patients with RCTA commonly underwent prior soft tissue mobilization and rotator cuff manipulation, which are thought to affect prosthetic implant stabilization and may play a role in the increased dislocation, infection, and bleeding rates [28].

Arthroscopic intervention for shoulder osteoarthritis has been used as a measure to temporize pain or mechanical symptoms in order to delay joint arthroplasty and expedite time to return to recreational activities and physically demanding jobs [17]. However, it was found that patients with history of PSA were risky to PRCs after TSA, similar to our prior finding that prior knee arthroscopy conferred high risk of PRCs after TKA [38]. Furthermore, PSA has also been reported to be associated with a higher risk of infection after shoulder arthroplasty [17]. On the basis of this association, surgeons should proceed with increased caution before performing an arthroplasty procedure in a patient with a history of PSA, and consider a lower threshold to rule out infection as well as the perioperative usage of antibiotic [17]. It has 
been shown that blood transfusion confers increased risk of PJI and mechanical complications within 2 years after shoulder arthroplasty and is associated with in-hospital PRCs after THA or TKA [22, 38, 39]. Consistent with previous literatures, blood transfusion was the only one factor in this study significantly associated with in-hospital PRCs following TSA among the perioperative complications. Specifically, allogeneic blood transfusion may have an immunomodulatory effect that may lower the threshold for PJI through several mechanisms $[22,38]$.

The main strengths of the current study include its both large-scale sample and national representativeness with the power to investigate rare events, and the utilization of multivariable regression modeling to reduce confounding $[31,33,38]$. However, several limitations still require mention, mainly inherent to the use of the NIS database. First, misclassification or discrepancy in the process of coding and documentation may be produced as with any large administrative database $[16,17,33,38$, 39]. Second, only in-hospital information of each patient is recorded, meaning any complication or adverse outcome that occurs after discharge such as readmission, functional status, and long-term follow-up can not be obtained in this database. This limitation may cause underestimating the incidence of PRCs $[8,9,26,29,33,38,39]$. Furthermore, only variables provided by the NIS database could be assessed. There are other potential procedural and component characteristics that possibly affect PRCs were unable to capture via the NIS database, such as surgical approach, length of surgery, type of anesthesia, amount of blood loss, cemented or uncemented components, and implant design [7-9, 15, $35,38,39,47]$.

\section{Conclusion}

In-hospital PRCs are disastrous and costly complications occurring after TSA with a total incidence of 1\%. The annual incidence of PRCs decreased from 2010 to 2014 with a surpassing 2.5-fold reduction. Dislocation was the most common PRCs, followed by PJI, PPF, and mechanical loosening. Several risk factors of PRCs after TSA were identified in our study including younger age ( $<64$ years), female, the native American, hospital in the South, alcohol abuse, depression, uncomplicated diabetes, diabetes with chronic complications, fluid and electrolyte disorders, metastatic cancer, neurological disorders, and renal failure. Advanced age ( $\geq 65$ years) and proprietary hospital were found as protective factors. In addition, PRCs were associated with other indications for TSA (AN, RA, and RCTA), Parkinson's disease, prior shoulder arthroscopy, and blood transfusion. Patients with PRCs after TSA demonstrated significantly more total charges and slightly longer LOS while less usage of Medicare.

\section{Abbreviations}

PRCs: prosthesis-related complications

TSA: total shoulder arthroplasty

NIS: Nationwide Inpatient Sample 
LOS: length of stay

PJI: periprosthetic joint infection

PPF :periprosthetic fracture

ICD-9-CM: International Classification of Diseases (ninth revision) Clinical Modification

RSA :reverse shoulder arthroplasty

AN: aseptic necrosis

RA :rheumatoid arthritis

RCTA: rotator cuff tear arthropathy

PSA: prior shoulder arthroscopy

THA: total hip arthroplasty

TKA: total knee arthroplasty

\section{Declarations}

\section{Ethics approval and consent to participate}

Not applicable. This observational study used deidentified publicly available data, hence there was no requirement for consent to participate and it was deemed exempt by the ethics committee. All methods were performed in accordance with the relevant guidelines and regulations.

\section{Consent for publication}

Not applicable.

\section{Availability of data and materials}

The datasets generated during and analyzed during the current study are not publicly available due to Data Use Agreement and more information can be found in AHRQ HCUP (www.hcup-us.ahrq.gov).They are available from the corresponding author on reasonable request.

\section{Competing interests}

The authors declare that they have no competing interest.

\section{Funding}


This research did not receive any specific grant from funding agencies in the public, commercial, or notfor-profit sectors.

\section{Authors' contributions}

QY contributed to the study design, data acquisition and analysis, interpretation of results, and writing and revising the manuscript. HX and ZS contributed to the study design, interpretation of results, and reviewing the manuscript. SL and XW contributed to data acquisition, data analysis, and reviewing of the manuscript. JW contributed to the study design, interpretation of results, and reviewing the manuscript. All authors read and approved the final manuscript.

\section{Acknowledgements}

We express our sincere gratitude to Goodwill Hessian Health Technology Co. Ltd. (100007, Beijing, China.) for providing consultation and guidance on statistical analysis in this study.

\section{References}

1. Norris TR, lannotti JP. Functional outcome after shoulder arthroplasty for primary osteoarthritis: A multicenter study. J Shoulder Elbow Surg. 2002;11:130-5.

2. Orfaly RM, Rockwood CA, Esenyel CZ, Wirth MA. A prospective functional outcome study of shoulder arthroplasty for osteoarthritis with an intact rotator cuff. J Shoulder Elbow Surg. 2003;12:214.

3. Bohsali KI, Wirth MA, Rockwood CA. Current concepts review: Complications of total shoulder arthroplasty. J Bone Joint Surg Am, 2006;88:2279-92.

4. Farley KX, Wilson JM, Kumar A, Gottschalk MB, Daly C, Sanchez-Sotelo J, et al. Prevalence of Shoulder Arthroplasty in the United States and the Increasing Burden of Revision Shoulder Arthroplasty. JB JS Open Access. 2021; 6:e20.00156.

5. Kircher J, Ohly B, Fal MF, Magosch P, Mauch F. Analysis of revision shoulder arthroplasty in the German nationwide registry from 2014 to 2018. JSES Int. 2021;5:382-90.

6. Leong NL, Sumner S, Gowd A, Nicholson GP, Romeo AA, Verma NN. Risk Factors and Complications for Revision Shoulder Arthroplasty. HSS J. 2020;16:9-14.

7. Wilson JM, Holzgrefe RE, Staley CA, Karas S, Gottschalk MB, Wagner ER. The effect of operative time on early postoperative complications in total shoulder arthroplasty: An analysis of the ACS-NSQIP database. Shoulder Elbow. 2021;13:79-88.

8. Smucny M, Menendez ME, Ring D, Feeley BT, Zhang AL. Inpatient surgical site infection after shoulder arthroplasty. J Shoulder Elbow Surg. 2015;24:747-53.

9. Li X, Veltre DR, Cusano A, Yi P, Sing D, Gagnier JJ, et al. Insurance status affects postoperative morbidity and complication rate after shoulder arthroplasty. J Shoulder Elbow Surg. 2017;26:142331. 
10. Padegimas EM, Maltenfort M, Ramsey ML, Williams GR, Parvizi J, Namdari S. Periprosthetic shoulder infection in the United States: Incidence and economic burden. J Shoulder Elbow Surg. 2015;24:7416

11. Hatta T, Werthel JD, Wagner ER, Itoi E, Steinmann SP, Cofield RH, et al. Effect of smoking on complications following primary shoulder arthroplasty. J Shoulder Elbow Surg. 2017;26:1-6.

12. Wang CA, Palmer JR, Madden MO, Cohen-Levy W, Vakharia RM, Roche MW. Perioperative complications in patients with sleep apnea following primary total shoulder arthroplasty: An analysis of 33,366 patients. J Orthop. 2019;16:382-5.

13. Kusin DJ, Ungar JA, Samson KK, Teusink MJ. Body mass index as a risk factor for dislocation of total shoulder arthroplasty in the first 30 days. JSES Open Access. 2019;3:179-82.

14. Burrus MT, Werner BC, Cancienne JM, Gwathmey FW, Brockmeier SF. Shoulder arthroplasty in patients with Parkinson's disease is associated with increased complications. J Shoulder Elbow Surg. 2015;24:1881-7.

15. Casp AJ, Montgomery SR, Cancienne JM, Brockmeier SF, Werner BC. Osteoporosis and ImplantRelated Complications After Anatomic and Reverse Total Shoulder Arthroplasty. J Am Acad Orthop Surg. 2020;28:121-7.

16. Tyrrell Burrus M, Cancienne JM, Boatright JD, Yang S, Brockmeier SF, Werner BC. Shoulder Arthroplasty for Humeral Head Avascular Necrosis Is Associated With Increased Postoperative Complications. HSS J. 2018;14:2-8.

17. Wright-Chisem J, Apostolakos JM, Dines JS, Dines DM, Gulotta L V., Taylor SA, et al. The impact of prior ipsilateral arthroscopy on infection rates after shoulder arthroplasty. J Shoulder Elbow Surg. 2021;30:1596-602.

18. Chalmers PN, Gupta AK, Rahman Z, Bruce B, Romeo AA, Nicholson GP. Predictors of Early Complications of Total Shoulder Arthroplasty. J Arthroplasty. 2014;29:856-60.

19. Malcolm TL, Chatha K, Breceda AP, Guo E, Friedman DJ, Sabesan VJ, et al. The impact of solid organ transplant history on inpatient complications, mortality, length of stay, and cost for primary total shoulder arthroplasty admissions in the United States. Shoulder Elbow Surg. 2018;27:1429-36.

20. Lung BE, Bisogno M, Kanjiya S, Komatsu DE, Wang ED. Early postoperative complications and discharge time in diabetic patients undergoing total shoulder arthroplasty. J Orthop Surg Res. 2019;14:1-8.

21. Smith JM, Cancienne JM, Brockmeier SF, Werner BC. Vitamin D deficiency and total shoulder arthroplasty complications. Shoulder Elbow. 2021;13:99-105.

22. Grier AJ, Bala A, Penrose CT, Seyler TM, Bolognesi MP, Garrigues GE. Analysis of complication rates following perioperative transfusion in shoulder arthroplasty. J Shoulder Elbow Surg. 2017;26:12039.

23. Walters JD, Denard PJ, Brockmeier SF, Werner BC. The relationship of bilateral shoulder arthroplasty timing and postoperative complications. J Shoulder Elbow Surg. 2021;30:317-23. 
24. Wagner ER, Houdek MT, Schleck CD, Harmsen WS, Sánchez-Sotelo J, Cofield R, et al. The role age plays in the outcomes and complications of shoulder arthroplasty. J Shoulder Elbow Surg. 2017;26:1573-80.

25. Park KJ, Menendez ME, Barnes CL. Perioperative Periprosthetic Fractures Associated With Primary Total Hip Arthroplasty. J Arthroplasty. 2017;32:992-5.

26. Ponce BA, Oladeji LO, Raley JA, Menendez ME. Analysis of perioperative morbidity and mortality in shoulder arthroplasty patients with preexisting alcohol use disorders. J Shoulder Elbow Surg. 2015;24:167-73.

27. Murphy AB, Menendez ME, Watson SL, Ponce BA. Metabolic syndrome and shoulder arthroplasty: epidemiology and peri-operative outcomes. Int Orthop. 2016;40:1927-33.

28. Lung BE, Kanjiya S, Bisogno M, Komatsu DE, Wang ED. Preoperative indications for total shoulder arthroplasty predict adverse postoperative complications. JSES Open Access. 2019;3:99-107.

29. Schairer WW, Nwachukwu BU, Lyman S, Craig E V., Gulotta L V. National utilization of reverse total shoulder arthroplasty in the United States. J Shoulder Elbow Surg. 2015;24:91-7.

30. Matsen FA, Li N, Gao H, Yuan S, Russ SM, Sampson PD. Factors affecting length of stay, readmission, and revision after shoulder arthroplasty a population-based study. J Bone Joint Surg Am. 2014;97:1255-63.

31. Schwartz AM, Farley KX, Boden SH, Wilson JM, Daly CA, Gottschalk MB, et al. The use of tobacco is a modifiable risk factor for poor outcomes and readmissions after shoulder arthroplasty Aims. Bone Joint J. 2020;102:1549-54.

32. Roddy E, Ma G, Zhang AL, Feeley BT, Ma CB, Lansdown DA. Outcomes of acute but not delayed reverse total shoulder arthroplasty for proximal humerus fracture are equal to those for rotator cuff arthropathy. Semin Arthroplasty. 2021;31:412-21.

33. Jiang JJ, Toor AS, Shi LL, Koh JL. Analysis of perioperative complications in patients after total shoulder arthroplasty and reverse total shoulder arthroplasty. J Shoulder Elbow Surg. 2014;23:18529.

34. Schiffman CJ, Hannay WM, Whitson AJ, Neradilek MB, Matsen FA, Hsu JE. Impact of previous nonarthroplasty surgery on clinical outcomes after primary anatomic shoulder arthroplasty. J Shoulder Elbow Surg. 2020;29:2056-64.

35. Somerson JS, Hsu JE, Neradilek MB, Matsen FA. Analysis of 4063 complications of shoulder arthroplasty reported to the US Food and Drug Administration from 2012 to 2016. J Shoulder Elbow Surg. 2018;27:1978-86.

36. Althoff AD, Reeves RA, Traven SA, Wilson JM, Woolf SK, Slone HS. Smoking is associated with increased surgical complications following total shoulder arthroplasty: an analysis of 14,465 patients. J Shoulder Elbow Surg. 2020;29:491-6.

37. Botros M, Curry EJ, Yin J, Jawa A, Eichinger JK, Li X. Reverse shoulder arthroplasty has higher perioperative implant complications and transfusion rates than total shoulder arthroplasty. JSES Open Access. 2019;3:108-12. 
38. Yang Q, Wang J, Xu Y, Chen Y, Lian Q, Zhang Y. Incidence and risk factors of in-hospital prosthesisrelated complications following total hip arthroplasty: a retrospective Nationwide Inpatient Sample database study. Orthop Surg. 2021;13:1579-86.

39. Yang Q feng, Lin Z ming, Yang S, Wang P kai, Chen R, Wang J. Incidence and Risk Factors of InHospital Prosthesis-Related Complications Following Total Knee Arthroplasty: A Retrospective Nationwide Inpatient Sample Database Study. Int Orthop. 2020;44:2243-52.

40. Browne JA, Sandberg BF, D'Apuzzo MR, Novicoff WM. Depression is associated with early postoperative outcomes following total joint arthroplasty: A nationwide database study. J Arthroplasty. 2014;29:481-3.

41. Losina E, Wright EA, Kessler CL, Barrett JA, Fossel AH, Creel AH, et al. Neighborhoods matter: Use of hospitals with worse outcomes following total knee replacement by patients from vulnerable populations. Arch Intern Med. 2007;167:182-7.

42. Menendez ME, Ring D, Barnes CL. Inpatient Dislocation After Primary Total Hip Arthroplasty. J Arthroplasty. 2016;31:2889-93.

43. Weatherby PJ, Efejuku TA, Somerson JS. Complications After Anatomic Shoulder Arthroplasty: Revisiting Leading Causes of Failure. J Arthroplasty. 2016;31:2889-93.

44. Menendez ME, Baker DK, Fryberger CT, Ponce BA. Predictors of extended length of stay after elective shoulder arthroplasty. J Shoulder Elbow Surg. 2015;24:1527-33.

45. Lunati MP, Wilson JM, Farley KX, Gottschalk MB, Wagner ER. Preoperative depression is a risk factor for complication and increased health care utilization following total shoulder arthroplasty. $J$ Shoulder Elbow Surg. 2021;30:89-96.

46. Kong L, Cao J, Zhang Y, Ding W, Shen Y. Risk factors for periprosthetic joint infection following primary total hip or knee arthroplasty: a meta-analysis. Int Wound J. 2017;14:529-36.

47. Ponce BA, Menendez ME, Oladeji LO, Soldado F. Diabetes as a risk factor for poorer early postoperative outcomes after shoulder arthroplasty. J Shoulder Elbow Surg. 2014;23:671-8.

\section{Figures}




\begin{tabular}{|c|c|}
\hline $\begin{array}{c}34,268 \text { records identified } \\
\text { through database }\end{array}$ & \\
\hline & Age data loss $(n=18)$ \\
\hline \multirow{2}{*}{$\begin{array}{c}34,268 \text { records screened } \\
\text { by metadata }\end{array}$} & Age $<18$ years $(n=7)$ \\
\hline & Patients with pathologic fracture of \\
\hline & humerus ( $n=41)$ \\
\hline 34,198 records included & Patients with osteomyelitis $(n=5)$ \\
\hline in final data analysis & \\
\hline
\end{tabular}

Figure 1

Process to screening data. 


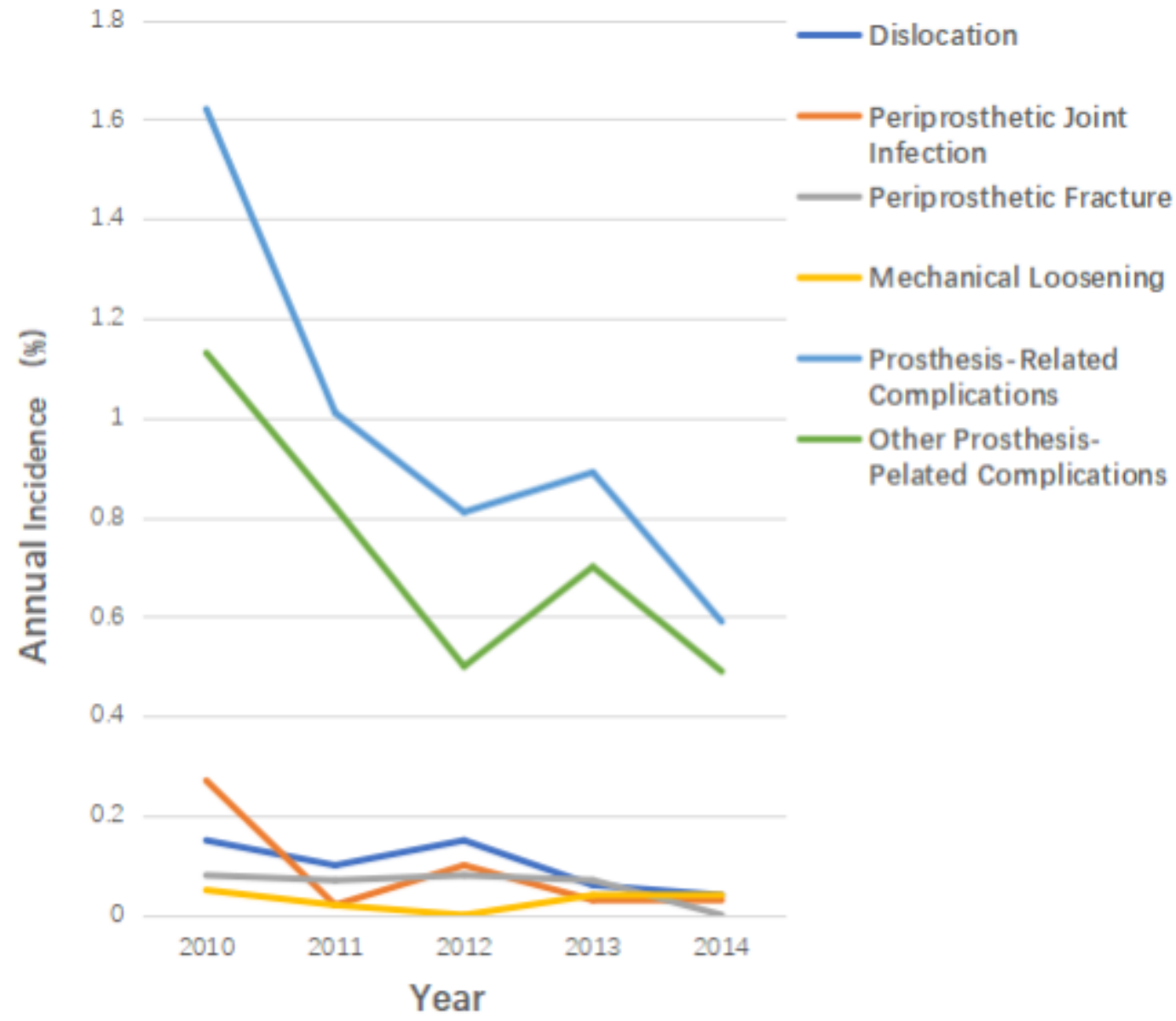

Figure 2

Annual incidence of in-hospital prosthesis-related complications following total shoulder arthroplasty. This indicates that the incidence of in-hospital PRCs which include periprosthetic joint infection, mechanical loosening, dislocation, periprosthetic fracture, and others, decreases from 2010 (1.62\%) to $2014(0.59 \%)$. 


\section{Prosthesis-Related Complications}

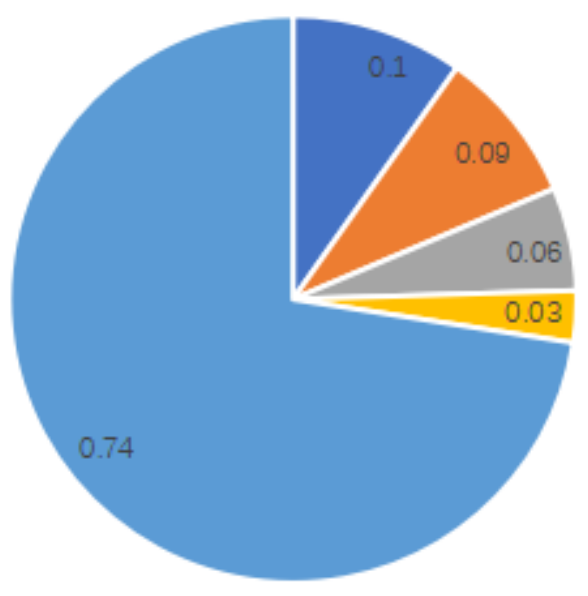

- Dislocation (\%)

- Periprosthetic Joint Infection (\%)

- Periprosthetic Fracture (\%)

- Mechanical Loosening (\%)

. Other Prosthesis-Related Complications (\%)

\section{Figure 3}

Incidence of specific categories among prosthesis-related complications following total shoulder arthroplasty. This shows that dislocation $(0.1 \%)$ was the most common PRCs followed by periprosthetic joint infection $(0.09 \%)$, periprosthetic fracture $(0.06 \%)$, and mechanical loosening $(0.03 \%)$ except for the miscellaneous $(0.74 \%)$.

\section{Supplementary Files}

This is a list of supplementary files associated with this preprint. Click to download.

- Additionalfile1.doc 